\title{
O sentido das marcas de moda: editoriais de moda numa perspectiva semiótica
}

The meaning of fashion brands: fashion editorials in a semiotic perspective

BISCHOFF, Bruna Marina; Mestranda; Universidade do Estado de Santa Catarina

brunamar@gmail.com

MACHADO, Bruna Rosa; Mestranda; Universidade do Estado de Santa Catarina

brunarosamachado@gmail.com

TAVARES, Carolina Savioli Marques; Mestranda; Universidade do Estado de Santa Catarina carol.tavares.itu@gmail.com

SCOZ, Murilo; Prof. Dr.; Universidade do Estado de Santa Catarina

muriloscoz@gmail.com

\section{Resumo}

Esta pesquisa analisa, através da semiótica greimasiana, os arranjos discursivos produtores de sentido presente em editoriais de moda. Estes, não apenas se apresentam como peças publicitárias, mas também como ferramentas de demonstração e prescrição de modos de ser e parecer, cumprindo assim seu papel dentro do sistema de difusão de moda. Objetiva-se entender de que forma as estratégias de persuasão convergem para educar os leitores sobre os modos de saber e dever vestir. Volta-se o olhar para as revistas de moda masculina, tendo como corpus o editorial "Questão de Classe", da revista GQ Brasil em sua edição de agosto de 2017, que utiliza a coleção de inverno 2017/18 da marca Giorgio Armani. Discutem-se os três níveis do Percurso Gerativo de Sentido, observando as reiterações do plano do conteúdo em relação à oposição semântica. Estas relações permitem a observação da construção da revista GQ como guia de estilo masculino.

Palavras Chave: análise semiótica, revista masculina, design de moda.

\begin{abstract}
This research analyzes, through the greimasian semiotics, the discursive arrangements that produce meaning in fashion editorials. These, do not present themselves only as advertising pieces, but also as tools of demonstration and prescription of ways of being and seem, fulfilling their role within the fashion diffusion system. It aims to understand how persuasion strategies converge to educate readers about ways of knowing and dressing. This analysis turns to men's fashion magazines, having as corpus the editorial "Questão de Classe", from the GQ Brazil magazine in its edition of August 2017, which uses the winter collection 2017/18 of the Giorgio Armani brand. The three levels of the Generative Course of Meaning are discussed, observing the reiterations of the Plan of Content in relation to the semantic opposition. These relations allow the observation of the construction of the GQ magazine as a male style guide.
\end{abstract}

Keywords: semiotic analysis, male magazine, fashion design. 


\section{Introdução}

A constante substituição de produtos, estilose, por conseguinte, modos de ser, é característica indissociável da indústria da moda. Para as engrenagens desta dinâmica autofágica operarem com precisão e eficiência, garantindo a circulação das mercadorias e o estímulo contínuo à demanda, é preciso que múltiplos atores colaborem entre si. O objetivo comum é não apenas difundir, mas também construir um sentido de legitimidade de novas propostas estéticas ligadas às práticas vestimentares, de modo a atrair o interesse do público consumidor. Sendo assim, para o lançamento de uma nova moda (ou modo), é preciso reconhecer que um tal sistema se apoia no esgotamento de uma proposta já estabelecida - a moda "antiga" - tendo seu potencial já sido explorado. O novo, que precisa apresentar-se com caráter de ruptura, se torna agora a regra, o que pressupõe um grande esforço da indústria e do varejo para a sua consolidação.

O surgimento das revistas de moda está justamente ligado ao processo de aumento da velocidade e do volume difundido de informação de moda que circula. Historicamente, este processo remonta à lógica que surge na corte francesa sob Luis XIV, com a ascensão da altacostura que evidenciava o desejo dos nobres da corte por trajes distintivos, bem como o intuito de expandir a moda francesa para um público maior. É neste momento que se desenvolve o conceito de estações dentro da indústria do vestuário, que por sua vez cria uma audiência para informação de moda. Conforme afirma DeJean (2010), é em 1672 que Jean Donneau de Visé lança o jornal Le Mercure Galant, dedicado a noticiar variedades, sendo o primeiro veículo a cobrir o cenário de moda francês. Posteriormente, em 1770 e 1786, são lançadas as primeiras revistas da área, respectivamente a inglesa Lady's Magazine e a alemã Jounal des Luxus und der Moden (SVENDSEN, 2010), responsáveis por informar as variações das práticas vestimentares vigentes. Observa-se que a maior parte destes veículos era dedicada ao público feminino e que somente em 1920 surgem as revistas especializadas em moda masculina. O papel destas publicações para a área da moda é como ferramenta de informação quanto a estilos e correntes estéticas, mas sob essa perspectiva também se caracteriza como instância normatizadora, já que edita e seleciona as silhuetas, cores, formas e conteúdos que seus leitores devem seguir a cada estação.

Desde este período, é inegável o fato de que as mulheres têm se mantido como a parcela de público consumidor mais importante para a moda. Porém, nos últimos anos, observa-se um crescimento no gasto masculino com itens do vestuário e também de higiene e beleza. De acordo com a empresa de consultoria e marketing Bain \& Company, o mercado global de moda masculina tem crescido em média $14 \%$ ao ano, percentual que representa quase o dobro do crescimento no segmento feminino. No Brasil, este mercado já constitui cerca de $30 \%$ da produção setorial, conforme afirma Stephan (2014). A respeito dos itens de higiene e beleza, ao contrário da crença popular, 93\% dos homens escolhem as marcas dos seus produtos e $83 \%$ efetivam sua próprias compras (STEPHAN, 2014). A partir de indicadores tão expressivos quanto ao desenvolvimento do mercado consumidor masculino e dos sinais de um crescente interesse em informação de moda, ganham relevo os estudos sobre as estratégias de sensibilização de tal público, que podem ser tomadas como práticas discursivas. Assim, a presente pesquisa concentra-se em editoriais fotográficos de revistas masculinas de moda, analisando a maneira como tais manifestações engendram efeitos de sentido e constroem sua narratividade, com o objetivo de demonstrar o caráter prescritivo de tais objetos. Para tal fim, o trabalho se vale dos preceitos da semiótica francesa, linha teórica dedicada aos processos de significação, tomando como corpus de análise 
um editorial fotográfico da grife Giorgio Armani da edição setenta e dois da revista GQ Brasil. Publicado em agosto de 2017 e intitulado "Questão de Classe", o editorial em questão se apresenta como objeto sincrético, configurando-se pela combinação entre enunciados verbais e visuais. Sendo assim, e para fins de análise, o modelo semiótico do Percurso Gerativo de Sentido é empregado, visto possibilitar a apreciação das estruturas semio-narrativas do texto, bem como sua articulação com os elementos plásticos do plano da manifestação, conforme o princípio da solidariedade entre expressão e conteúdo. A definição deste corpus de análise levou em consideração aspectos relativos à importância do periódico no mercado brasileiro, ao seu posicionamento (dedicado à moda masculina) e à sua representatividade para o público em questão (número de leitores exclusivamente masculinos).

A seguir, no sentido de explicitar o aparato teórico-metodológico, serão apresentados os níveis do Percurso Gerativo com o registro das observações realizadas a partir do texto analisado, o que permite, ao final, a discussão acerca das estratégias de construção do caráter prescritivo da moda.

\section{Metodologia e objeto de estudo}

Esta análise apropria-se da semiótica francesa, também conhecida como greimasiana ou discursiva, que possibilita o estudo dos processos de produção dos sentidos nos mais diversos textos. Tendo suas origens na obra de A. J. Greimas, a teoria busca analisar diferentes manifestações, sendo estas tomadas enquanto todos de sentido. Segundo Bertrand (2003):

A semiótica apresenta modelos para a análise da significação, para além da palavra, para além da frase, na dimensão do discurso que lhe é inerente. Seu procedimento clássico propõe articular a apreensão do sentido segundo um percurso estratificado em camadas relativamente homogêneas, indo de formas concretas e particulares, manifestadas na superfície do texto, às formas mais abstratas e gerais subjacentes (BERTRAND, 2003, p. 43).

A semiótica discursiva parte do princípio da articulação entre o plano do conteúdo e o plano da expressão na leitura de textos e práticas. Neste estudo, tendo em vista o recorte metodológico, será levado em conta o conjunto das relações estabelecidas na dimensão do plano do conteúdo, em que operam as categorias figurativo-narrativas. Para a teoria semiótica, este plano pode ser esquematizado num percurso gerativo, que consiste em "uma sucessão de patamares, cada um dos quais mais suscetível de receber uma descrição adequada, que mostra como se produz e se interpreta o sentido, num processo que vai do mais simples ao mais complexo" (FIORIN, 2002, p. 20). O quadro abaixo faz referência aos níveis do percurso, cada qual decomponível em suas respectivas dimensões sintáticas e semânticas.

Quadro 1 - Percurso Gerativo de Sentido

\begin{tabular}{|c|c|c|}
\hline NÍVEL & SINTAXE & SEMÂNTICA \\
\hline DISCURSIVO & Relações na instância da Enunciação & $\begin{array}{c}\text { Operações de figurativização e } \\
\text { tematização. }\end{array}$ \\
\hline NARRATIVo & $\begin{array}{c}\text { Percurso Narrativo (Manipulação, Competência, } \\
\text { Performance e Sanção) }\end{array}$ & $\begin{array}{c}\text { Construção dos objetos modal e } \\
\text { de valor. }\end{array}$ \\
\hline
\end{tabular}




\begin{tabular}{|l|c|c|}
\hline FUNDAMENTAL & $\begin{array}{c}\text { Operações de negação e asserção dos termos da } \\
\text { semântica fundamental. }\end{array}$ & Oposição semântica de base. \\
\hline
\end{tabular}

Fonte: Fiorin (2002), adaptado pelos autores (2017).

A estrutura gerativa dos textos parte, então, do mais profundo e simples dos níveis, o fundamental, ao mais superficial e complexo, o discursivo. Para Fiorin (2002, p. 20), cada nível possui uma dimensão semântica e outra sintática, sendo a primeira relativa aos investimentos semânticos nos termos do conteúdo, enquanto a segunda refere-se mais diretamente às relações entre tais termos.

Tomados como textos, os editoriais fotográficos podem ser analisados a partir justamente desta lógica semiótica, dado que decorrem de estratégias discursivas e intenções mercadológicas. Isto porque as revistas de moda em que figuram "não só permitem documentar o surgimento de novos padrões, como influenciam de maneira determinante nessas escolhas" (SOUZA E CUSTÓDIO, 2005, p. 241). Elas são, portanto, relevante ferramenta na disseminação de ideias e estilos, fazendo uso de diversas linguagens na valoração dos produtos mostrados.

Como já colocado, para a definição da revista masculina que é o ponto de partida da presente análise foi considerado o posicionamento da publicação. Por questões de relevância geográfica, optou-se por uma publicação do mercado brasileiro e cujo conteúdo fosse majoritariamente dedicado à moda. Por fim, outro ponto de corte importante relacionou-se à proporção de leitores do sexo masculino da revista, taxa esclarecida pelos dados bibliográficos sobre sua tiragem e distribuição.

A Revista GQ (Gentlemen's Quaterly) é de origem americana, mas há seis anos possui uma edição brasileira de conteúdos mistos. A temática da GQ é o estilo de vida masculino, e a revista se apresenta como "o guia essencial de estilo, cultura e lifestyle do homem brasileiro sofisticado" conforme informação expressa no seu Mídia Kit, que evidencia seu caráter didático. O editorial "Questão de Classe", da edição número setenta e dois, apresenta-se em seis páginas da revista, sendo composto principalmente por fotos de página inteira e pequenos textos verbais. Os textos verbais, quando aplicados, são periféricos e diagramados próximos aos modelos fotografados, sem que haja sobreposição e de modo a não interferir na visualização das roupas. São apresentadas cinco fotografias, sendo apenas a primeira delas em formato paisagem e disposta em página dupla. Os modelos vestem a coleção de inverno 2017/18 da marca Giorgio Armani, num ensaio ambientado em espaços urbanos, tanto exteriores quanto interiores. Além de textos introdutórios, título e descrição de preços das roupas, as páginas possuem citações atribuídas ao próprio estilista Giorgio Armani que contextualizam e reforçam as ideias passadas pelo editorial. Considerando que "nas revistas, o conteúdo não é apenas o texto que se lê, mas tudo aquilo que nele se insere e dele se deduz" (SOUZA E CUSTÓDIO, 2005, p. 239), a perspectiva semiótica se torna relevante para compreender como a totalidade de sentido é construída em um objeto sincrético como este editorial de moda, o qual reúne diversas linguagens com o intuito de construir um simulacro de estilo - uma prescrição - para o leitor.

\section{Os sentidos no editorial "Questão de Classe"}


A partir do quadro conceitual proposto, passamos a percorrer os elementos do editorial "Questão de Classe", da edição do mês de setembro de 2017 da revista GQ Brasil.

Imagens 1, 2, 3, 4, 5 e 6 - Páginas sequenciais do editorial “Questão de Classe"
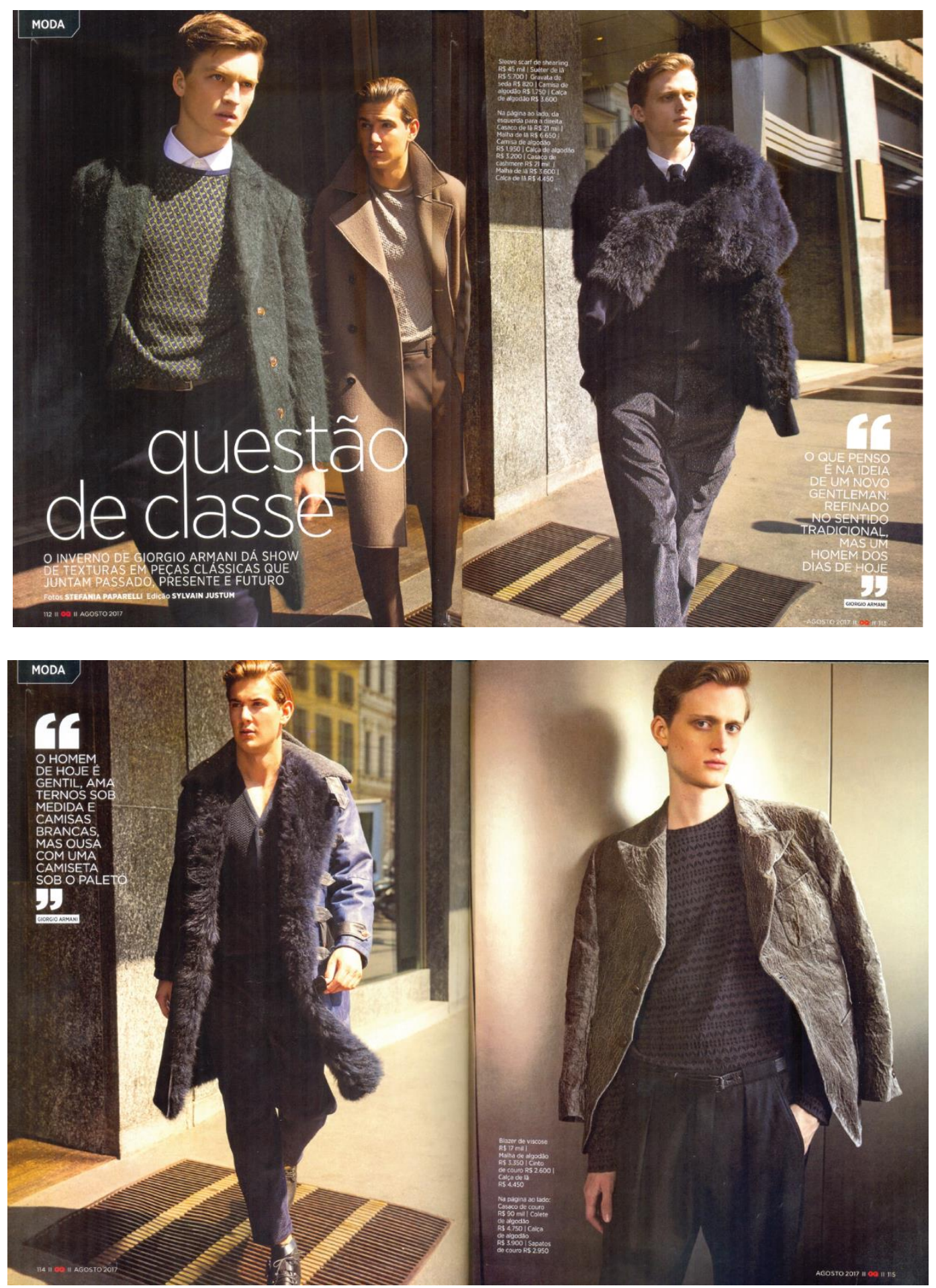


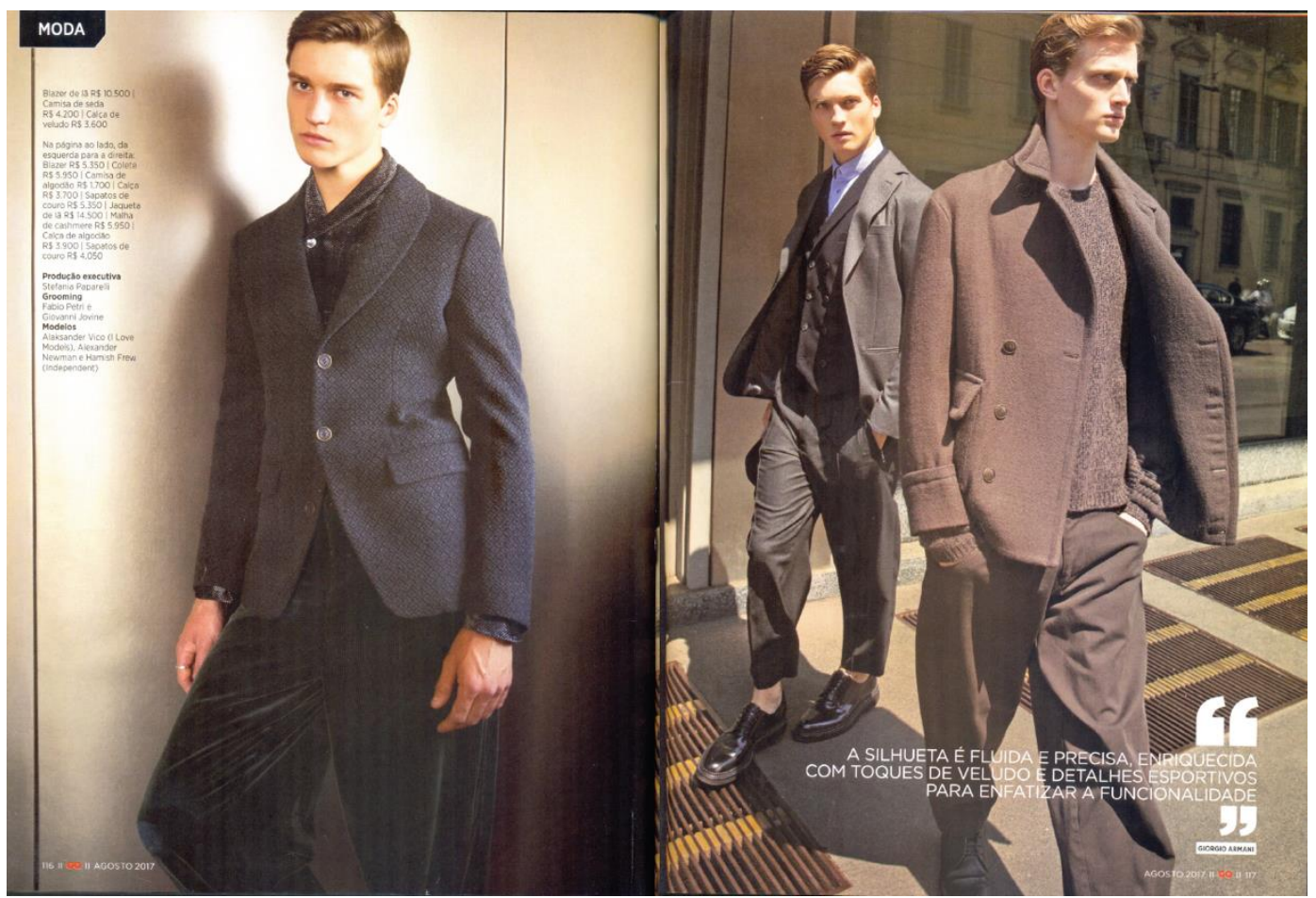

Fonte: Revista GQ, edição de agosto de 2017.

\subsection{Nível discursivo}

O nível discursivo é o mais superficial do percurso, através do qual o texto revela os aspectos mais concretos de sua construção. Nele, a dimensão semântica abarca os investimentos figurativos e temáticos do discurso, que dizem respeito respectivamente às figuras (elementos concretos do mundo real que o texto recupera e que, portanto, podem ser reconhecidos) e aos temas (elementos abstratos que se relacionam às figuras utilizadas). Já na sintaxe deste nível, temse as relações da instância da enunciação, construídas por operações de actorialização, temporalização e espacialização.

Cabe à sintaxe do discurso explicar as relações do sujeito da enunciação com o discursoenunciado e também as relações que se estabelecem entre enunciador e enunciatário. $O$ discurso define-se, ao mesmo tempo, como objeto produzido pelo sujeito da enunciação e como objeto de comunicação entre um destinador e um destinatário (BARROS, 2005, p.50).

No caso do editorial analisado, a revista GQ e a marca de moda italiana Giorgio Armani compõem o papel do enunciador, sincretizado através do editorial. Aqui, temos um processo de delegação de voz, em que a revista abre espaço para as falas do estilista da marca. Desta feita, a revista explora e afirma o seu caráter didático de "guia" ao permitir que a marca explique imagética e textualmente os atributos e os elementos vestimentares que devem ser conhecidos (consumidos) pelo enunciatário, que guarda relação com o simulacro do consumidor da revista.

É notório que no mercado mundial a marca Giorgio Armani é referência em bem vestir para o público masculino, gozando de um estatuto validado por múltiplas instâncias midiáticas e sociais. No editorial em tela, as citações atribuídas ao estilista da maison o apresentam como o 
"fiador" do estilo proposto, fazendo com que a revista ancore-se na reputação daquele a quem a voz é delegada. Isto porque, conforme os trechos em destaque, o sujeito que se apresenta nas falas escolhidas pela revista já é reconhecido como alguém competencializado por um saber e que, por associação, também competencializa a revista para cumprir o seu papel de media. Nas citações diretas nos enunciados verbais que se sobrepõem às imagens, a revista abre espaço para que a marca exponha diretamente (como que sem mediação) seus conceitos e saberes: "O que penso é na ideia de um novo gentleman: refinado no sentido tradicional, mas um homem dos dias de hoje." (...) "O homem de hoje é gentil, ama ternos sob medidas e camisas brancas, mas ousa com uma camiseta sob o paletó." Aqui evocada como uma espécie de personificação do próprio simulacro da marca, a figura do estilista Giorgio Armani expressa uma visão específica sobre um certo perfil identitário, que dá contornos ao homem contemporâneo.

Através deste procedimento, temos então um processo de legitimação recíproca, tanto de um estilista modalizado cognitivamente, quanto de um periódico investido da capacidade pragmática do fazer "didático", esperado de um guia de estilo. Portanto, mencionar a marca e seu criador por meio de depoimentos é uma forma da GQ garantir a relevância da estética que está sendo retratada. Imageticamente, a utilização das roupas da marca na composição do editorial ilustra este ideal de elegância, materializado nos cortes assinados pelo estilista.

Em relação à semântica do nível discursivo, Castilho e Martins (2008) esclarecem a forma como se apresenta esta camada do texto:

Estudam-se a organização das figuras e os temas que a elas subjazem que vão recuperar concretamente os termos encontrados no primeiro nível da geração de sentido e que passaram por novos revestimentos semânticos no nível das estruturas narrativas (CASTILHO; MARTINS, 2005 p.75).

Ante o exposto, apresenta-se um quadro com as principais referências em relação à dois temas recorrentes na superfície discursiva do editorial: elementos que se referem ao antigo (ou tradicional) e outros que sugerem o novo, depreendidos a partir de figuras específicas:

Quadro 2 - Relação entre Temática e Figuratividade no editorial "Questão de Classe".

\begin{tabular}{|l|l|}
\hline \multirow{2}{*}{ TEMÁTICA } & FIGURATIVIDADE \\
\hline \multirow{3}{*}{} & Roupas de alfaiataria; \\
\cline { 2 - 2 } & Peças com texturas de pele, lã, veludo, tricôs; \\
\cline { 2 - 3 } & Uso de trajes com 3 peças; \\
\cline { 2 - 3 } & Reflexo de prédios com arquitetura européia, nas Imagens 3 e 6. \\
\hline \multirow{2}{*}{ NOVO } & Homens jovens esbeltos e sem barba; \\
\hline
\end{tabular}




\begin{tabular}{|c|}
\hline Calçados sem meias; \\
\hline Suéter sem camiseta por baixo, na Imagem 3; \\
\hline Fundo aço escovado, superfície lisa, nas Imagens 4 e 5 ; \\
\hline Comprimento mais curto das calças, nas Imagens 3 e 4; \\
\hline Fotos em movimento, modelos caminhando (street style); \\
\hline Combinação de peças com texturas diversas; \\
\hline $\begin{array}{l}\text { Prédios com arquitetura minimalista, moderna, utilizando materiais } \\
\text { como vidro, concreto e aço escovado, nas Imagens } 2,3 \text { e } 4 \text {. }\end{array}$ \\
\hline
\end{tabular}

Fonte: desenvolvido pelos autores (2018).

Esta dualidade figurativa está relacionada a três "superfícies" do texto, que são os corpos dos modelos, as roupas e tecidos, e a ambientação das fotografias. Nos corpos dos modelos essa dualidade se evidencia quanto à jovialidade, penteado e ausência de barba; nas roupas, são as texturas, modelagens e combinações que expressam o encontro da tradição com a ruptura; e na ambientação, edifícios que indiciam uma arquitetura europeia contrasta com o contemporâneo que se revela através do vidro e as texturas das paredes e calçadas.

\subsection{Nível narrativo}

Segundo a teoria semiótica, a narratividade é uma qualidade textual ligada ao conceito da transformação, podendo esta ser complexa e estruturada em uma sequência canônica, composta pelas fases da manipulação, competência, performance e sanção (FIORIN, 2002). Uma abordagem deste nível é observada a partir da relação estabelecida entre revista-leitor, ou seja, voltando-se o olhar para a transformação pressuposta no editorial analisado para aqueles que a consomem. 0 conjunto de imagens de um editorial escapa à descrição mais simples do que se toma como uma narrativa, visto que há certa dificuldade em considerar as imagens como uma sequência de eventos, encadeadas segundo uma linearidade temporal, diferentemente da lógica que se observa por exemplo em outros textos visuais complexos, como os quadrinhos e outras formas de arte sequencial. Assim, para além da descrição de possíveis esquemas narrativos contidos na trajetória dos modelos masculinos retratados nas fotos, o presente estudo examina a construção deste texto verbo-visual enquanto expressão orientadora de consumo, gosto e estilo para seus leitores. Logo, a narratividade se articula na dinâmica entre o enunciador (que propõe o arranjo estético como uma moda) e o enunciatário (de quem se espera a adesão a tal arranjo).

A partir da sequência canônica mencionada anteriormente, a primeira etapa do esquema narrativo é a manipulação, quando um "sujeito age sobre outro para levá-lo a querer e/ou dever fazer alguma coisa" (FIORIN, 2002 p.29). Destaca-se que essa influência não está necessariamente investida de valor negativo, mas refere-se a qualquer interação em que um sujeito age sobre o outro (CASTILHOS; MARTINS, 2005). Portanto a ação pode ser desencadeada por um convite, 
pedido, chamado, entre outros. Semioticamente, estão previstos quatro tipos de manipulação: tentação, intimidação, sedução e provocação. Já que a dinâmica da prática, do ato de adquirir e ler a revista, é de interesse deste nível da análise, retoma-se o posicionamento da GQ como "o guia essencial de estilo, cultura e lifestyle do homem brasileiro sofisticado" e entende-se que a manipulação se dá por tentação, pois a recompensa contida na promessa de conteúdo da revista é de orientar seus leitores para que alcancem o ideal de sofisticação por ela promovido. Identificase, assim, um objeto de valor positivo que se pretende oferecer pela manipulação.

$\mathrm{Na}$ fase seguinte do percurso canônico, o "sujeito da performance é dotado das competências necessárias para a transformação que realizará, isto é, as modalidades do poder ou do saber fazer" (CASTILHOS; MARTINS, 2005 p.71). Sendo assim, compreende-se o sujeito da performance como o leitor, o qual adquire o saber fazer através de um conjunto de códigos vestimentares apresentados pela GQ. Voltando-se para a especificidade do editorial analisado, a legitimação do discurso apresentado é realizada por meio da delegação de voz para o estilista Giorgio Armani. Por meio de tal estratégia discursiva, constrói-se o sentido de verdade dos parâmetros apresentados. Nestes termos, é a partir da reputação da marca Armani e de seu criador que a revista se edifica neste texto como guia: existe uma terceirização da expertise para qualificar a informação veiculada.

Considerando os temas e figuras apresentadas no nível discursivo, retoma-se que a competência expressa no editorial é a de domínio do estilo, que apresenta em certa medida uma ruptura com a tradição. $O$ uso das peças de alfaiataria, ternos de três peças, modelos com cabelos rigorosamente alinhados e outras figuras previamente mencionadas remetem ao tema do antigo, tradicional e clássico. Dentro do código do bem vestir masculino, estas são práticas já estabelecidas. Porém, as imagens também exibem o uso de sapatos sem meia, calças com o comprimento mais curto e a combinação de texturas diversas no arranjo dos looks. Dessa forma, a competência a que o editorial se refere é a de domínio de um estilo híbrido. As normas clássicas do vestir masculino são atualizadas para uma composição mais contemporânea a partir de pequenas transgressões de determinadas regras, que são apresentadas para o leitor como o ideal do "novo gentleman" a partir da perspectiva de Giorgio Armani. O sujeito que lê/vê o editorial se competencializa quando versado nessas nuances estéticas.

A terceira etapa do percurso narrativo é a performance, caracterizada como "a fase em que se dá a transformação (mudança de um estado a outro) central da narrativa" (FIORIN, 2002 p.31). A partir dessa definição e do objeto em questão, considera-se que a forma mais evidente da performance é a incorporação do estilo proposto pela revista no guarda-roupa do leitor, comprando as peças divulgadas e adotando as combinações aprendidas. Contudo, parece ainda mais importante ressaltar que este indivíduo estaria competencializado a reconhecer em seus pares práticas vestimentares associadas ao bem vestir.

A sanção é a última fase do percurso narrativo. Se caracteriza pelo reconhecimento da performance, quando é ratificada, ou não, a transformação do sujeito (FIORIN, 2002). Na dinâmica revista-leitor, a sanção pode ser entendida como a construção do indivíduo que domina os códigos vestimentares vigentes e passa a ser reconhecido pelos seus pares como alguém que conhece moda, tem estilo e atinge os ideais de sofisticação propostos pela GQ. Entretanto, estar a par do que "está" na moda não se esgota, pois esta se renova constantemente. Evidencia-se, assim, a sanção como uma etapa narrativa fugidia de ser atingida, pois não se edifica em um saber fazer estável. A cada estação, ou ainda em períodos mais curtos, surgem novas silhuetas, formas e 
combinações que são promovidas como vigentes. Consequentemente, os consumidores estão em processo incessante de atualização. Dado o exposto, argumenta-se que o percurso canônico não chega ao seu fim inteiramente, já que a sanção, observada nesta prática, é pautada na própria efemeridade da moda.

Segundo Fiorin (2002, p.36), na sintaxe do nível narrativo, observa-se o encadeamento dos papéis narrativos, enquanto a semântica trata dos valores inscritos nos objetos. Existem, pois, dois tipos de objetos: os modais e os de valor. O objeto modal é aquele "cuja aquisição é necessária para realizar a performance principal" (FIORIN, 2002, p. 37) e depreende-se, neste texto, como o saber fazer. É a habilidade de assimilar as informações, prescrições, compor e se portar como este homem que equilibra o clássico com o novo, numa identidade sustentada por Giorgio Armani. Ademais, pela apresentação destes conteúdos, a revista também se constrói como vetor de moda, ou seja, na condição de objeto modal para determinado público que se pretende competente sobre tais preceitos estéticos. Aqui, retomando a ideia de uma sanção que não está dada, o objeto de valor desta análise também possui caráter fugidio.

\subsection{Nível fundamental}

No nível fundamental do Percurso Gerativo de Sentido são identificadas as categorias semânticas mais profundas, sobre as quais as demais estruturas do percurso estão a assentes. Essas categorias podem ser esquematizadas enquanto uma oposição que organiza os valores do texto. "Os termos opostos de uma categoria semântica mantém entre si uma relação de contrariedade. São contrários os termos que estão em uma relação de pressuposição recíproca" (FIORIN, 2002). A oposição entre os elementos indica que um necessita do outro para completar e explicar seu próprio sentido e, que assumem valores de /euforia/ versus /disforia/ de acordo com as relações dentro do texto.

Em relação à sintaxe, o nível fundamental pressupõe operações de negação e asserção dos termos da categoria. A partir de tais operações, a semântica fundamental propõe o modelo do quadrado semiótico, representação gráfica que se estrutura a partir de relações de oposição, implicação e contradição. Abaixo apresenta-se o quadrado semiótico referente aos conceitos apreendidos no editorial "Questão de Classe":

Imagem 1 - Quadrado Semiótico do editorial "Questão de Classe”

\section{CONTEMPORÂNEO}

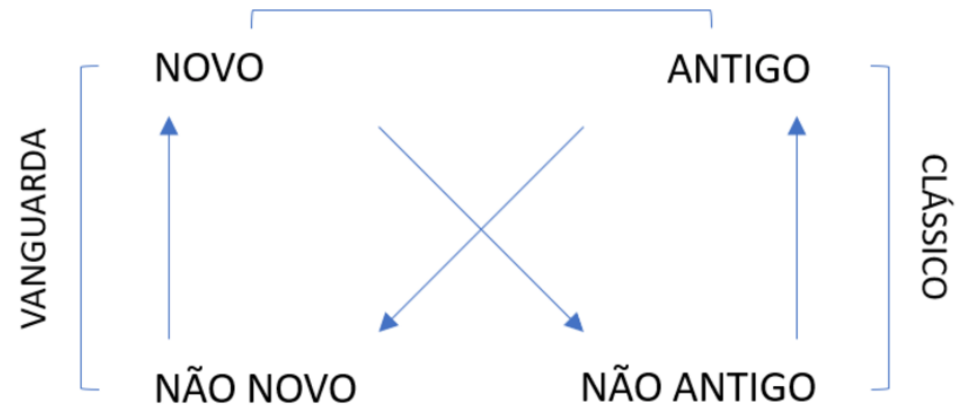

ANTIQUADO 
Fonte: desenvolvido pelos autores (2018).

Pelo exposto, a categoria /novo/ versus /antigo/, se dá a perceber inicialmente pelos textos verbais que acompanham as imagens. De uma forma quase didática, estes enunciados explicam que as peças clássicas da Armani "[...] juntam passado, presente e futuro" enquanto propõem "[...] um novo gentleman: refinado no sentido tradicional, mas um homem dos dias de hoje". Nestas duas primeiras falas, percebe-se que a tensão entre os termos da categoria é neutralizada no conceito complexo /contemporâneo/, cerne da ideia de sofisticação e classe que a marca deseja transmitir. Na terceira fala o texto explicita figurativamente esta proposta, tratando do parecer e do vestidor do homem contemporâneo: "O homem de hoje é gentil, ama ternos sob medida e camisas brancas, mas ousa com uma camiseta sob o paletó".

Assim, o contemporâneo euforizado neste editorial não se resume pela expressão do novo, mas pelo sentido de compatibilização entre modos opostos do vestir masculino, que revisita e reformula o clássico em diferentes combinações. Isso é reiterado pela ambientação, que combina, por exemplo, o vidro das vitrines e as pedras das fachadas dos edifícios, a descontinuidade entre o cimento da calçada e as bocas-de-lobo. Da mesma forma, a juventude sóbria dos modelos também exemplifica esta reformulação do tradicional.

\section{Considerações finais}

A teoria semiótica greimasiana se mostrou eficiente para cumprir a proposta da análise, uma vez que oferece mecanismos suficientes para que se esgote a discussão em relação ao objetivo que fora proposto: o de entender como as estratégias de produção de sentido foram utilizadas com o intuito de educar os leitores acerca de maneiras de saber e dever vestir, sendo a revista parte integrante do sistema da moda e responsável por naturalizar preceitos estéticos.

O editorial "Questão de Classe" apresenta orientações sobre moda masculina ao empregar arranjos persuasivos de maneira menos evidente e imperativa que outras seções da revista. Para tanto, faz uso da delegação de voz ao Giorgio Armani para operar seu caráter normativo, explicando como tal estética deve ser adotada. A partir dos discursos verbais atribuídos ao estilista, que possui uma reputação respeitável na moda masculina, a revista legitima o estilo expresso imageticamente e também valida e qualifica o seu papel de guia de estilo para o homem contemporâneo.

A tematização do novo e antigo é figurativizada pela oposição entre: cabelos penteados com gel, uso de trajes com três peças, roupas de alfaiataria com modelagens clássicas, texturas de lã, pele e veludo, cores escuras, ambientação com reflexos de arquitetura européia; e modelos sem barba, jovens, utilizando calçado sem meias, calças de comprimento curto, camiseta por baixo do suéter, composições fotográficas que são comumente apresentadas como street style, combinação de texturas, ambientação minimalista utilizando materiais como vidro, concreto e aço escovado.

O objeto modal observado é o domínio dos códigos vestimentares correntes pelo leitor, enquanto o objeto de valor almejado é esta construção identitária como um homem na moda. Porém, em virtude da própria efemeridade da moda, observa-se que a conquista deste ideal não se realiza inteiramente. A revista reitera seu papel como guia ao apresentar as ferramentas 
necessárias para que seu leitor se transforme, aceitando a manipulação para se tornar um homem contemporâneo aos moldes dos conceitos expressos pela marca Armani.

Finalmente, no nível mais abstrato da análise, revela-se a oposição semântica de base /novo/ versus /antigo/, que, ao ser interpretada no quadrado semiótico (novo - não novo - antigo não antigo), caracterizam o termo complexo contemporâneo: o ideal de vestir e parecer para o homem dos dias atuais. Implica-se que este homem é investido do saber mesclar e combinar devidamente elementos do novo e do antigo, sendo este último constantemente revisitado e relido para compor o primeiro com maestria.

Tomando em consideração os conceitos da sociossemiótica, o editorial analisado pode ir além do estudo de textos semióticos, se configurando em uma prática do mundo vivido, uma vez que ele é um gesto enunciativo entre a revista $\mathrm{GQ}$, a marca Armani e o consumidor. O leitor, desta forma, leva as definições de gosto e estilo apresentadas para sua vida real. A Revista GQ se posiciona de forma a reiterar o didatismo em seu conceito de guia, delegando ao simulacro da marca Giorgio Armani a função e a autoridade em demonstrar de que forma o consumidor da revista deve se portar e vestir para estar competencializado a ser um "homem contemporâneo".

\section{Referências}

A BARROS, Diana Luz Pessoa. Teoria semiótica do texto. 4. ed. Ed. Ática, 2005.

BERTRAND, Denis. Caminhos da semiótica literária. São Paulo: EDUSC, 2003.

CASTILHO, Kathia; MARTINS, Marcelo M. Discursos da moda: semiótica, design e corpo. São Paulo: Anhembi, 2008.

DEJEAN, Joan E. A essência do estilo: como os franceses inventaram a alta-costura, a gastronomia, os cafés chiques, o estilo, a sofisticação e o glamour. Rio de Janeiro: Civilização Brasileira, 2010.

FIORIN, José Luiz. Elementos de análise do discurso. 11. ed. São Paulo: Contexto, 2002.

JUSTUM, Sylvain; PAPARELLI, Stefania. Questão de Classe. GQ Brasil, n.77, p.112-117, ago.2017.

Mídia Kit GQ. Disponível em http://editora.globo.com/midiakit/gq/midiakit_gq.pdf. Acesso em: 30 ago. 2017.

SOUZA, Valdete Vazzoler de; CUSTÓDIO, José de Arimathéia Cordeiro. Fotografia: meio e linguagem dentro da moda. Revista Discursos Fotográficos, v.1, p. 231-251, 2005.

SVENDSEN, Lars. Moda: uma filosofia. Rio de Janeiro: J. Zahar, 2010.

STEPHAN, Paulo. Os homens mudaram. São Paulo: Dash. 2014. 